\title{
Removal of Organic Dyes by Nanostructure ZnO-Bamboo Charcoal Composites with Photocatalysis Function
}

\author{
Xinliang Yu, ${ }^{1}$ Aimiao Qin, ${ }^{1}$ Lei Liao, ${ }^{2}$ Rui Du, ${ }^{1}$ Ning Tian, ${ }^{1}$ Song Huang, ${ }^{1}$ and Chun Wei ${ }^{1}$ \\ ${ }^{1}$ Key Lab New Processing Technology for Nonferrous Metals \& Materials, Ministry of Education, \\ College of Materials Science \& Engineering, Guilin University of Technology, No. 12 Jiangan Road, Guilin 541004, China \\ ${ }^{2}$ College of Environmental Science \& Engineering, Guilin University of Technology, No. 12 Jiangan Road, Guilin 541004, China
}

Correspondence should be addressed to Aimiao Qin; 592491245@qq.com

Received 23 July 2014; Revised 19 December 2014; Accepted 8 January 2015

Academic Editor: Hao Wang

Copyright (C) 2015 Xinliang Yu et al. This is an open access article distributed under the Creative Commons Attribution License, which permits unrestricted use, distribution, and reproduction in any medium, provided the original work is properly cited.

\begin{abstract}
Composites of nanostructure zinc oxide (nano- $\mathrm{ZnO}$ ) and bamboo charcoal (BC) were successfully prepared via impregnationprecipitation method. The products were characterized by XRD, SEM, and EDS. Rhodamine B (RhB) and acid fuchsin (AF) were selected as the organic dyes of photocatalysis degradation under the irradiation of ultraviolet light (UV). The influence of particle size of $\mathrm{BC}$, irradiation time, $\mathrm{pH}$ value of the solution, and additive amount of $\mathrm{H}_{2} \mathrm{O}_{2}$ on removal of the dyes has been studied. The results show that smaller particle size of $\mathrm{BC}$ in the composites has a better removal effect. The composites possess the highest removal capacity for $\mathrm{RhB}$ and $\mathrm{AF}$ under the conditions of $\mathrm{pH}=2$ and $\mathrm{pH}=5.4$, respectively. The optimum additive amount of $\mathrm{H}_{2} \mathrm{O}_{2}$ for $5 \mathrm{~mL} \mathrm{RhB}$ and $\mathrm{AF}$ was $0.050 \mathrm{~mL}$ and $0.1 \mathrm{~mL}$, with a removal rate of $93 \%$ and $99 \%$, respectively.
\end{abstract}

\section{Introduction}

Nano- $\mathrm{ZnO}$ is considered to be one of the most promising highly active photochemical catalysts for its advantages such as high efficiency, energy saving, cleaning, nontoxicity, and no secondary pollution [1]. In the past few years, the study on its preparation method and catalytic performance has been one of the hot areas of research activities [2-4]. The photocatalysis mechanism is that, under irradiation of light, $\mathrm{ZnO}$ is emitted to produce a large number of electron-hole pairs in which the electrons have strong reducibility and the holes have strong oxidizability. Due to the oxidation of $\mathrm{OH}$ - and $\mathrm{H}_{2} \mathrm{O}$ molecules by the holes, highly active hydroxyl free radicals $\left({ }^{\circ} \mathrm{OH}\right)$ with strong oxidizability generate. Subsequently, organics are oxidized by ${ }^{\circ} \mathrm{OH}$ and ultimately degraded into $\mathrm{CO}_{2}, \mathrm{H}_{2} \mathrm{O}$, and other nontoxic inorganic small molecules [5]. At present, photocatalysis applications of $\mathrm{ZnO}$ concentrated on the sewage treatment and removal of interior organic contaminants $[6,7]$. Most of the organics in the water can be oxidized and removed, including chloroform, carbon tetrachloride, and trichloroethylene, which are difficult to eliminate through traditional water treatment methods. In addition, heavy metal ions in the water can also be reduced by the electrons in the conduction band without affecting the beneficial mineral elements for human beings [8-10]. However, actual applications of powdery nanometer oxide photocatalysts are limited due to some disadvantages such as low light utility efficiency, difficulties in separation, and recovery [11]. Further researches will focus on development of novel nano- $\mathrm{ZnO}$ material which is easier to commercially produce accompanied with lower energy consumption and higher photocatalytic activity.

Bamboo charcoal (BC) prepared from pyrolysis of bamboo presents a porous structure with a surface area of $360 \mathrm{~m}^{2} / \mathrm{g}$ and even $1000 \mathrm{~m}^{2} / \mathrm{g}$ if further treated, which is 25 times higher than that of the ordinary carbon [12]. Owing to the specific structure characteristics, $\mathrm{BC}$ exhibits strong adsorption performance to many kinds of contamination in air and water, and thus it can be applied in air purification, sewage filtering, and food preservation as a new functional material [13-15]. However, BC is unsuitable to be used alone as an adsorbent because of the secondary pollution caused by the incomplete removal of pollutants. Besides, its adsorption performance will decrease gradually as time goes on.

With synergistic reaction of absorption of $\mathrm{BC}$ and catalytic degradation of nanophotocatalysts, study of 
nanomodified $\mathrm{BC}$ is believed to make good sense [16]. Chuang et al. [17], Zhou et al. [18], and Zhang et al. [19] have reported that nano- $\mathrm{TiO}_{2}$ modified $\mathrm{BC}$ has a good photocatalysis performance to lots of organic pollutants. However, as one of the most common semiconductor photocatalysts as $\mathrm{TiO}_{2}$, researches on nano- $\mathrm{ZnO}$ modified $\mathrm{BC}$ are very few. In fact, $\mathrm{ZnO}$ has a better photocatalysis performance than $\mathrm{TiO}_{2}$ under specific conditions [20-22]. As an efficient photocatalyst, $\mathrm{ZnO}$ would likely replace $\mathrm{TiO}_{2}$ in the future owing to the same band-gap energy, similar photocatalytic mechanism, and lower cost [23]. Our previous research showed that $\mathrm{ZnO} / \mathrm{BC}$ composites prepared via impregnation-precipitation method have a good removal rate of methylene blue by more than 95\% [24]. Rhodamine-B (RhB) and acid fuchsin (AF) are commonly used organic dyes in industry of spin printing and dyeing and biomedicine study. Due to the high concentration in the effluents and the higher stability of these modern synthetic dyes, the conventional biological treatment methods are ineffective for the complete removal and degradation, which are harmful to the environment and hazardous to human health. Therefore, the further study on the removal of another two basic organic dyes, $\mathrm{RhB}$ and $\mathrm{AF}$, was carried out.

\section{Materials and Experiments}

2.1. Reagents and Materials. In this paper, the following chemicals were used: zinc oxide $(\mathrm{ZnO}, \mathrm{AR}$, ShanTou West Long Chemical Co., Ltd.); polyethylene glycol-6000 (PEG6000, CP, Shantou West Long Chemical Co., Ltd.); sodium hydroxide $(\mathrm{NaOH}, \mathrm{AR}$, Guangdong Guanghua Chemical Factory Co., Ltd.); absolute ethyl alcohol $\left(\mathrm{C}_{2} \mathrm{H}_{5} \mathrm{OH}, \mathrm{AR}\right.$, Tianjin Damao Chemical Reagent Factory); bamboo charcoal (BC, Jiangmen Jinrong Household Products Co., Ltd.); rhodamine B (RhB, AR, Tianjin Institute of Chemical Reagents); acid fuchsin (AR, Shanghai SSS Reagent Co., Ltd.); hydrochloric acid ( $\mathrm{HCl}, 36-38 \%$, AR, ShanTou West Long Chemical Co., Ltd.); and hydrogen peroxide $\left(\mathrm{H}_{2} \mathrm{O}_{2}, 30 \%\right.$, AR, ShanTou West Long Chemical Co., Ltd.). Distilled water was used throughout the experiments.

2.2. Modification of BC by $\mathrm{ZnO}$ Nanoparticles. BC is modified by nano- $\mathrm{ZnO}$ via impregnation-precipitation method [25]. That is, BC as a carrier is soaked in soluble zinc salt solution for a period of time so that $\mathrm{Zn}^{2+}$ can be absorbed on the surface of $\mathrm{BC}$ adequately. Then $\mathrm{NaOH}$ as the precipitation agent is added into the solution to form precipitation with the absorbed $\mathrm{Zn}^{2+}$. Under the heating conditions, nano- $\mathrm{ZnO}$ generated and loaded on surface of BC.

In a typical experiment, $\mathrm{BC}$ was ground into powder and sieved to various particle sizes: $250-550 \mu \mathrm{m}, 120-250 \mu \mathrm{m}, 75-$ $120 \mu \mathrm{m}$, and less than $75 \mu \mathrm{m}$. $0.5 \mathrm{~g}$ as-prepared BC powder was dispersed in $30 \mathrm{~mL}$ mixed solution containing $0.2 \mathrm{~g}$ PEG6000 and $0.086 \mathrm{~g} \mathrm{ZnSO} \cdot 7 \mathrm{H}_{2} \mathrm{O}$ with distilled water as a solvent and stirred for $4 \mathrm{~h}$. Then $20 \mathrm{~mL} \mathrm{NaOH}(0.03 \mathrm{~mol} / \mathrm{L})$ was added dropwise into above mixture and kept on stirring for $8 \mathrm{~h}$. Next, the mixture was kept at $80^{\circ} \mathrm{C}$ for $50 \mathrm{~min}$. After cooling, the products were filtered and washed repeatedly

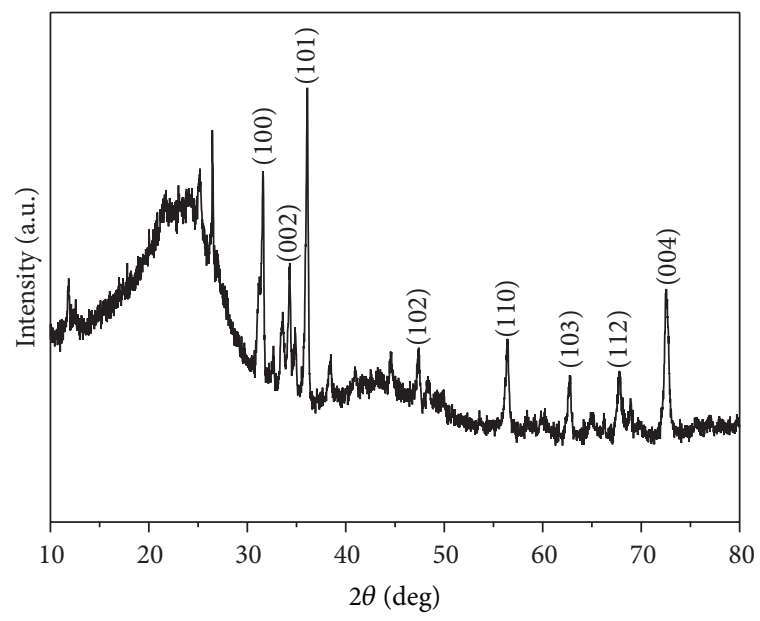

FIGURE 1: XRD pattern of the nano- $\mathrm{ZnO} / \mathrm{BC}$ composites.

with distilled water until $\mathrm{pH}=7$. The final composites were obtained by drying at $80^{\circ} \mathrm{C}$ for $12 \mathrm{~h}$.

2.3. Characterizations. The XRD patterns were recorded via X-ray diffractometer (Netherlands PANalytical Company). The SEM images were acquired on JSM-6380LV scanning electron microscope (NEC Electronics Corporation). Elemental analysis was taken by an OIMS energy dispersive X-ray spectroscopy and UV-VIS was tested on UV-3600 ultraviolet-visible spectrophotometer (Shimadzu Corporation) at a range of $200 \mathrm{~nm}$ to $800 \mathrm{~nm}$.

2.4. Removal of the Organic Dyes by Nano-ZnO/BC Composites. $2 \mathrm{mg} / \mathrm{L} \mathrm{RhB}$ and $20 \mathrm{mg} / \mathrm{L}$ AF solution were prepared firstly. Then $0.1 \mathrm{~g}$ nano- $\mathrm{ZnO} / \mathrm{BC}$ composites were added into $5 \mathrm{~mL}$ as-prepared organic dyes and the formed suspension system was irradiated by UV $(\lambda=254 \mathrm{~nm})$. After specific time, the liquid phase was separated by centrifuging $(10000 \mathrm{r} / \mathrm{min})$ and the absorbance was detected by UV-VIS.

According to Lambert-Beer's law [26], the removal rate of the dyes is calculated by the following formula:

$$
\text { Removal rate }(\%)=\frac{C_{0}-C}{C_{0}} \times 100 \%=\frac{A_{0}-A}{A_{0}} \times 100 \% \text {. }
$$

In this formula, $C_{0}$ and $C$ are defined as the initial concentration of the dyes and the concentration after photocatalysis reaction. $A_{0}$ and $A$ are defined as the initial absorbance and the absorbance after photocatalysis reaction.

\section{Results and Discussions}

3.1. Structure Analysis. Figure 1 shows the XRD patterns of the $\mathrm{ZnO} / \mathrm{BC}$ composites. Two broad peaks appearing around $24^{\circ}$ and $43^{\circ}$ indicate the typical peaks of amorphous carbon with noncrystalline structures. Typical characteristic peaks of $\mathrm{ZnO}$ can be observed on the diffraction patterns, which correspond to the (100), (002), (101), (102), (110), (103), (112), 




(a)

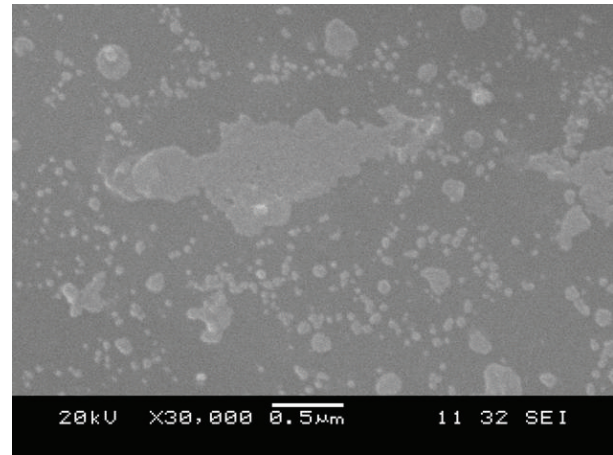

(b)

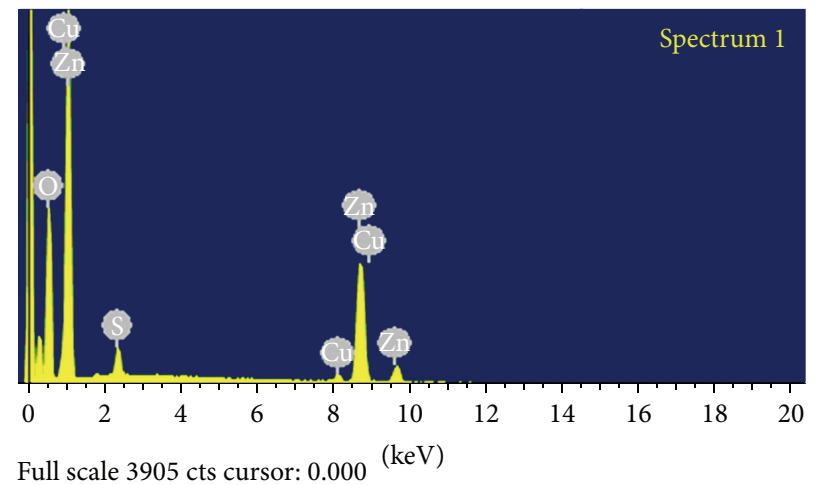

(c)

FIGURE 2: SEM images (a), (b) and EDS spectrum (c) of the nano- $\mathrm{ZnO} / \mathrm{BC}$ composites.

and (004) planes in the reference PDF card (JCPDS 89-0511). The XRD result suggests that $\mathrm{BC}$ is a typical amorphous carbon and $\mathrm{ZnO}$ is assigned to hexagonal zincite structure.

\subsection{Morphology and Component Analysis. The SEM images} and the EDS analysis of the composites are shown in Figure 2. Figure 2(a) illustrates that BC presents a typical honeycomb structure with a large number of macropores with the diameter of 1-15 $\mu \mathrm{m}$ on the cross section. Figure 2(b) reveals that $\mathrm{ZnO}$ particles are mostly less than $50 \mathrm{~nm}$ in diameter and some are aggregated because of the high surface energy. The EDS result in Figure 2(c) shows that, besides $\mathrm{Cu}$ introduced by sample stage, $\mathrm{O}$ and $\mathrm{Zn}$ are mainly detected and the calculated atom ratio is close to $1: 1$. A small amount of S may derive from $\mathrm{BC}$.

\subsection{Photodegradation Studies of the Organic Dyes}

3.3.1. Effect of Particle Size of BC. Table 1 presents the influence of particle size of $\mathrm{BC}$ on the removal of the organic dyes under $\mathrm{UV}$ for $15 \mathrm{~min}$. The removal rates of $\mathrm{RhB}$ and $\mathrm{AF}$ increase by $41.49 \%$ and $25.20 \%$ when the particle size of BC decreases from $250-550 \mu \mathrm{m}$ to $\leq 75 \mu \mathrm{m}$. The reason should be attributed to the stronger adsorption of the smaller particle with larger specific surface area. But if particle size is too small, preparation time will be longer and separation of the liquid-solid phase would be more difficult. So the particle size should be controlled to a specific region according to actual requirement.
TABLE 1: Influence of particle size of BC on removal of the organic dyes.

\begin{tabular}{lcc}
\hline Particle size $/ \mu \mathrm{m}$ & $\begin{array}{c}\text { Removal rate of } \\
\text { RhB/\% }\end{array}$ & $\begin{array}{c}\text { Removal rate of } \\
\text { AF/\% }\end{array}$ \\
\hline $250-550$ & 43.46 & 61.60 \\
$120-250$ & 54.32 & 73.76 \\
$75-120$ & 55.79 & 81.56 \\
$\leq 75$ & 84.95 & 86.80 \\
\hline
\end{tabular}

3.3.2. Effect of Time. The influence of irradiation time of UV on the removal of the organic dyes is shown in Figure 3. It can be seen that the removal rate increases rapidly in the beginning and becomes stable after $60 \mathrm{~min}$, which is because the concentration of the dyes falls down over time and the diffusion layer thickness surrounding the adsorbent particles decreases [27].

3.3.3. Effect of $p H$ Value. Figure 4 shows the influence of the $\mathrm{pH}$ value of the solution on the removal of the organic dyes under $\mathrm{UV}$ for $15 \mathrm{~min}$. The $\mathrm{pH}$ value was adjusted by $\mathrm{HCl}$ and $\mathrm{NaOH}$. It is clear that the removal rate of two organic dyes is affected greatly by $\mathrm{pH}$ value. At lower $\mathrm{pH}$ value, the removal rate of $\mathrm{RhB}$ is higher than that under neutral and alkaline condition. It should be noted that when the $\mathrm{pH}$ value is 2.0 , the removal rate reaches to $65 \%$ after only $15 \mathrm{~min}$ photocatalysis reaction. However, strong acid condition plays an opposite role in the removal of AF compared with $\mathrm{RhB}$. 


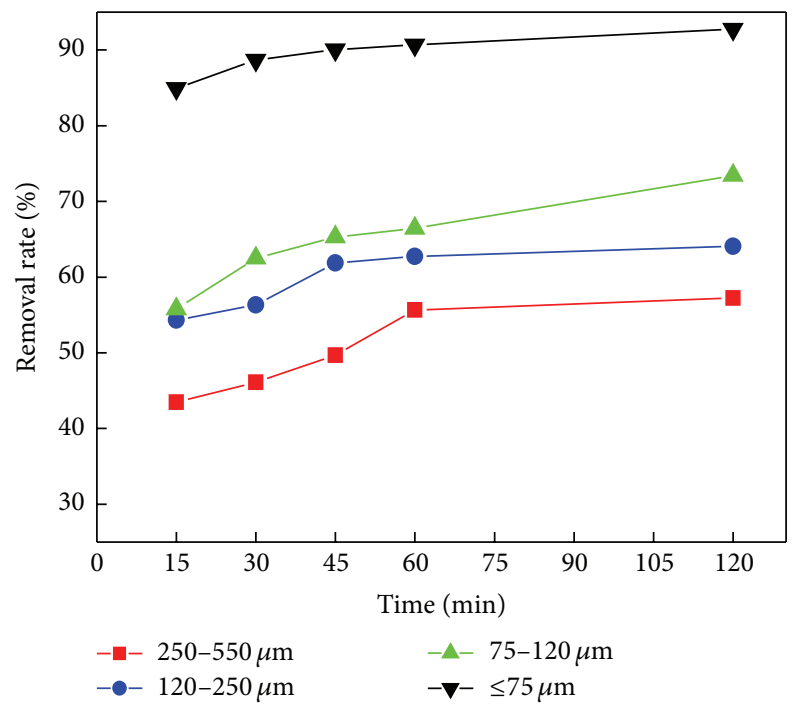

(a)

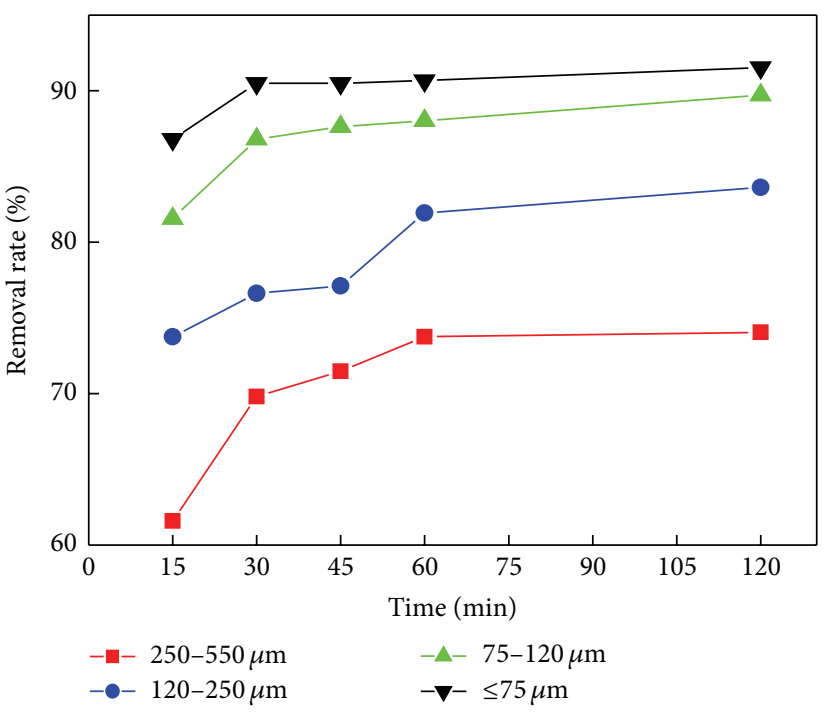

(b)

FIGURE 3: Influence of irradiation time of UV on the removal of the organic dyes by nano-ZnO/BC composites with different particle size of BC: (a) RhB, (b) AF.



(a)

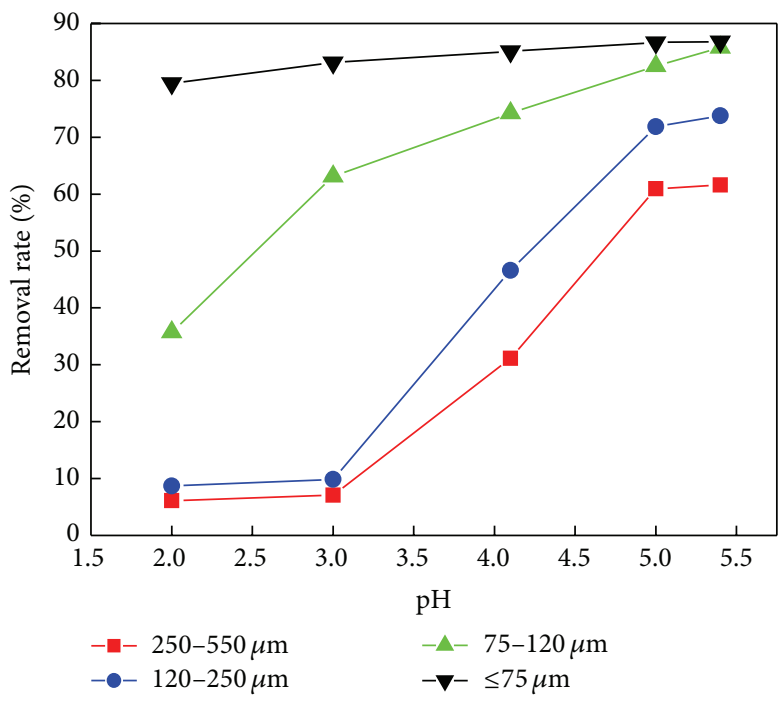

(b)

FIGURE 4: Influence of $\mathrm{pH}$ value on removal of the organic dyes by nano- $\mathrm{ZnO} / \mathrm{BC}$ composites with different particle size of BC: (a) RhB, (b) AF.

The removal rate of $\mathrm{AF}$ improves much as the $\mathrm{pH}$ value increases. Therefore, $\mathrm{pH}$ value has different influences on removal of different organic dyes, for it affects not only the surface properties of $\mathrm{ZnO}$ but also the dissociation of dye molecules and the formation of hydroxyl radicals [28].

3.3.4. Effect of Additive Amount of $\mathrm{H}_{2} \mathrm{O}_{2}$. Figure 5 shows the influence of additive amount of $\mathrm{H}_{2} \mathrm{O}_{2}$ on the removal of the organic dyes under UV for $15 \mathrm{~min}$. A considerable improvement of the removal rate can be observed due to an increase of ${ }^{\circ} \mathrm{OH}$ in the solution after a small amount of $\mathrm{H}_{2} \mathrm{O}_{2}$ is added. For $\mathrm{RhB}$, the removal rate reaches a relatively high level when the amount of $\mathrm{H}_{2} \mathrm{O}_{2}$ is $0.05 \mathrm{~mL}$. However, as concentration increases continuously, the removal rate begins to decrease. The reason may be that excess $\mathrm{H}_{2} \mathrm{O}_{2}$ acts as a hole or ${ }^{\bullet} \mathrm{OH}$ scavenger or reacts with $\mathrm{ZnO}$ and forms peroxo compounds, which are detrimental to the photocatalysis action [29]. For AF, the removal rate increases significantly when the additive amount of $\mathrm{H}_{2} \mathrm{O}_{2}$ is less than $0.1 \mathrm{~mL}$. It should be emphasized that when the particle size of $\mathrm{BC}$ is less than $75 \mu \mathrm{m}$, the removal rate of $\mathrm{AF}$ is close to $100 \%$ by the addition of only a little $\mathrm{H}_{2} \mathrm{O}_{2}$ solution. Therefore, more $\mathrm{H}_{2} \mathrm{O}_{2}$ is not necessarily better to assure a higher removal rate. To avoid waste, the optimum amount of $\mathrm{H}_{2} \mathrm{O}_{2}$ in this experiment is $0.05 \mathrm{~mL}$ and $0.1 \mathrm{~mL}$ for $5 \mathrm{~mL} \mathrm{RhB}$ and $5 \mathrm{~mL}$ AF. 


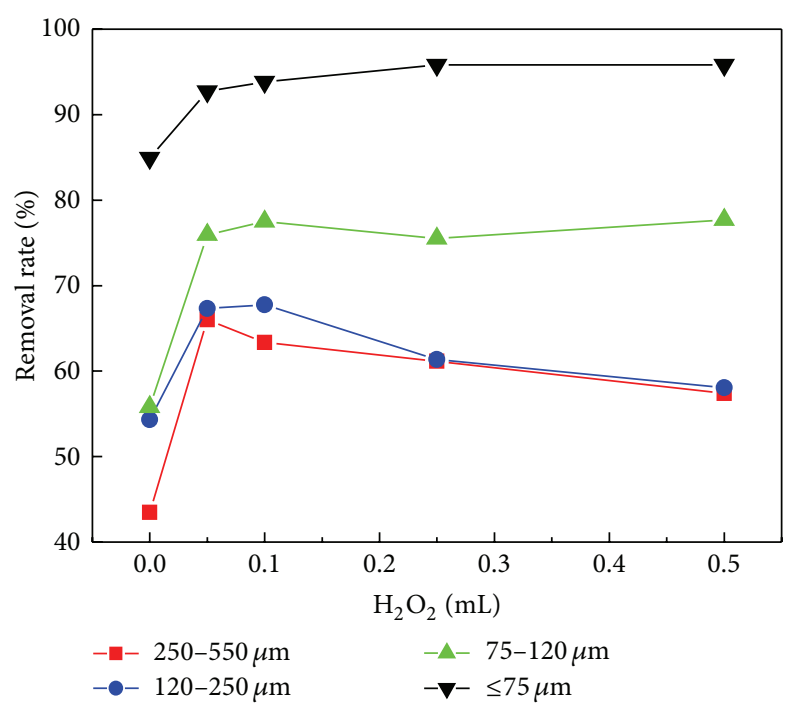

(a)

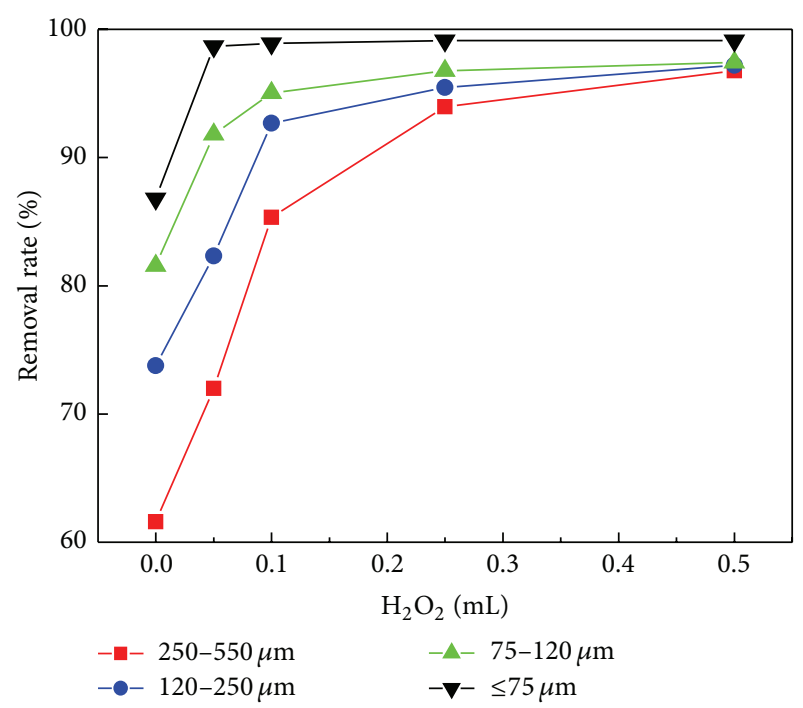

(b)

FIGURE 5: Influence of additive amount of $\mathrm{H}_{2} \mathrm{O}_{2}$ on removal of the organic dyes by nano- $\mathrm{ZnO} / \mathrm{BC}$ composites with different particle size of BC: (a) RhB, (b) AF.

\section{Conclusions}

Nano-ZnO/BC composites were prepared via impregnationprecipitation method. The impact factors such as particle size of $\mathrm{BC}$, irradiation time, $\mathrm{pH}$ value of solution, and additive amount of $\mathrm{H}_{2} \mathrm{O}_{2}$ on the photocatalysis properties of the composites are discussed. The results show that the as-prepared $\mathrm{ZnO} / \mathrm{BC}$ composites are assigned to wurtzite of hexagonal crystal structure. Smaller particle size of BC shows better removal effect on the dyes. The removal rate of $\mathrm{RhB}$ is much higher under strong acid condition but it is better for removal of AF under weak acid condition. In addition, a certain amount of $\mathrm{H}_{2} \mathrm{O}_{2}$ contributes to the removal of the dyes for the enhanced oxidation of solution.

\section{Conflict of Interests}

The authors declare that there is no conflict of interests regarding the publication of this paper.

\section{Acknowledgments}

This work was supported by the National Science Foundation of China (under Grants nos: 21063005, 50968005, 21264005, and 51163003) and by the National Science Foundation of Guangxi Province (2014GXNSFAA118331 and 2010GXNSFC013007).

\section{References}

[1] C. Tian, Q. Zhang, A. Wu et al., "Cost-effective large-scale synthesis of $\mathrm{ZnO}$ photocatalyst with excellent performance for dye photodegradation," Chemical Communications, vol. 48, no. 23, pp. 2858-2860, 2012.
[2] Z. L. Wang, "Ten years' venturing in $\mathrm{ZnO}$ nanostructures: from discovery to scientific understanding and to technology applications," Chinese Science Bulletin, vol. 54, no. 22, pp. 40214034, 2009.

[3] S. J. Pearton, D. P. Norton, K. Ip, Y. W. Heo, and T. Steiner, "Recent progress in processing and properties of $\mathrm{ZnO}$," Progress in Materials Science, vol. 50, no. 3, pp. 293-340, 2005.

[4] Z. Y. Fan and J. G. Lu, "Zinc oxide nanostructures: synthesis and properties," Journal of Nanoscience and Nanotechnology, vol. 5, no. 10, pp. 1561-1573, 2005.

[5] D. Li and H. Haneda, "Morphologies of zinc oxide particles and their effects on photocatalysis," Chemosphere, vol. 51, no. 2, pp. 129-137, 2003.

[6] J. Peral, X. Domènech, and D. F. Ollis, "Heterogeneous photocatalysis for purification, decontamination and deodorization of air," Journal of Chemical Technology and Biotechnology, vol. 70, no. 2, pp. 117-140, 1997.

[7] S. Lathasree, A. N. Rao, B. Sivasankar, V. Sadasivam, and K. Rengaraj, "Heterogeneous photocatalytic mineralisation of phenols in aqueous solutions," Journal of Molecular Catalysis A: Chemical, vol. 223, no. 1-2, pp. 101-105, 2004.

[8] A. A. Aal, S. A. Mahmoud, and A. K. Aboul-Gheit, "Nanocrystalline $\mathrm{ZnO}$ thin film for photocatalytic purification of water," Materials Science and Engineering C, vol. 29, no. 3, pp. 831-835, 2009.

[9] C. Hariharan, "Photocatalytic degradation of organic contaminants in water by $\mathrm{ZnO}$ nanoparticles: revisited," Applied Catalysis A: General, vol. 304, pp. 55-61, 2006.

[10] Z. Han, L. Liao, Y. Wu, H. Pan, S. Shen, and J. Chen, "Synthesis and photocatalytic application of oriented hierarchical $\mathrm{ZnO}$ flower-rod architectures," Journal of Hazardous Materials, vol. 217-218, pp. 100-106, 2012.

[11] O. Legrini, E. Oliveros, and A. M. Braun, "Photochemical processes for water treatment," Chemical Reviews, vol. 93, no. 2, pp. 671-698, 1993. 
[12] Q. S. Zhang, "Playing great attention on bamboo chemical processing and exploiting bamboo charcoal applying technique," Journal of Bamboo Research, vol. 20, pp. 34-43, 2001 (Chinese).

[13] S.-Y. Wang, M.-H. Tsai, S.-F. Lo, and M.-J. Tsai, "Effects of manufacturing conditions on the adsorption capacity of heavy metal ions by Makino bamboo charcoal," Bioresource Technology, vol. 99, no. 15, pp. 7027-7033, 2008.

[14] M. Wang, Z.-H. Huang, G. Liu, and F. Kang, "Adsorption of dimethyl sulfide from aqueous solution by a cost-effective bamboo charcoal," Journal of Hazardous Materials, vol. 190, no. 1-3, pp. 1009-1015, 2011.

[15] P. Liao, S. H. Yuan, W. J. Xie, W. Zhang, M. Tong, and K. Wang, "Adsorption of nitrogen-heterocyclic compounds on bamboo charcoal: kinetics, thermodynamics, and microwave regeneration," Journal of Colloid and Interface Science, vol. 390, no. 1, pp. 189-195, 2013.

[16] C. M. Lu, "Photocatalytic oxidation of propoxur insecticide with titanium dioxide supported on activated carbon," Journal of Environmental Science and Health Part B, vol. 34, pp. 207-223, 1999.

[17] C. S. Chuang, M.-K. Wang, C.-H. Ko, C.-C. Ou, and C.-H. $\mathrm{Wu}$, "Removal of benzene and toluene by carbonized bamboo materials modified with $\mathrm{TiO}_{2}$," Bioresource Technology, vol. 99, no. 5, pp. 954-958, 2008.

[18] J. B. Zhou, C. J. Deng, J. H. Fu, and Q. S. Zhang, "Adsorption and degradation of toluene over $\mathrm{TiO}_{2}$ supported on bamboo charcoal," Carbon, vol. 47, p. 2941, 2009.

[19] J. Zhang, D. Zhao, J. Wang, and L. Yang, "Photocatalytic oxidation of dibenzothiophene using $\mathrm{TiO}_{2}$ /bamboo charcoal," Journal of Materials Science, vol. 44, no. 12, pp. 3112-3117, 2009.

[20] C. Lizama, J. Freer, J. Baeza, and H. D. Mansilla, "Optimized photodegradation of reactive blue 19 on $\mathrm{TiO}_{2}$ and $\mathrm{ZnO}$ suspensions," Catalysis Today, vol. 76, no. 2-4, pp. 235-246, 2002.

[21] A. A. Khodja, T. Sehili, J.-F. Pilichowski, and P. Boule, "Photocatalytic degradation of 2-phenylphenol on $\mathrm{TiO}_{2}$ and $\mathrm{ZnO}$ in aqueous suspensions," Journal of Photochemistry and Photobiology A: Chemistry, vol. 141, no. 2-3, pp. 231-239, 2001.

[22] H.-L. Liu and T. C.-K. Yang, "Photocatalytic inactivation of Escherichia coli and Lactobacillus helveticus by $\mathrm{ZnO}$ and $\mathrm{TiO}_{2}$ activated with ultraviolet light," Process Biochemistry, vol. 39, no. 4, pp. 475-481, 2003.

[23] N. Daneshvar, D. Salari, and A. R. Khataee, "Photocatalytic degradation of azo dye acid red 14 in water on $\mathrm{ZnO}$ as an alternative catalyst to $\mathrm{TiO}_{2}$," Journal of Photochemistry and Photobiology A: Chemistry, vol. 162, no. 2-3, pp. 317-322, 2004.

[24] A. M. Qin, H. N. Chen, and P. Tang, in Proceedings of the 7th China Conference on Functional Materials and Applications, 3rd Section, 2010.

[25] H.-D. Zhuang, S.-F. Bai, X.-M. Liu, and Z.-F. Yan, "Structure and performance of $\mathrm{Cu} / \mathrm{ZrO}_{2}$ catalyst for the synthesis of methanol from $\mathrm{CO}_{2}$ hydrogenation," Journal of Fuel Chemistry and Technology, vol. 38, no. 4, pp. 462-467, 2010.

[26] J. D. Ingle and S. R. Crouch, Spectrochemical Analysis, Prentice Hall, Upper Saddle River, NJ, USA, 1988.

[27] C. Namasivayam and R. T. Yamuna, "Removal of Rhodamine-B by biogas waste slurry from aqueous solution," Water, Air, and Soil Pollution, vol. 65, no. 1-2, pp. 101-109, 1992.

[28] K. Byrappa, A. K. Subramani, S. Ananda, K. M. Lokanatha Rai, R. Dinesh, and M. Yoshimura, "Photocatalytic degradation of rhodamine B dye using hydrothermally synthesized $\mathrm{ZnO}$," Bulletin of Materials Science, vol. 29, no. 5, pp. 433-438, 2006.
[29] I. Poulios and I. Tsachpinis, "Photodegradation of the textile dye Reactive Black 5 in the presence of semiconducting oxides," Journal of Chemical Technology and Biotechnology, vol. 74, no. 4, pp. 349-357, 1999. 

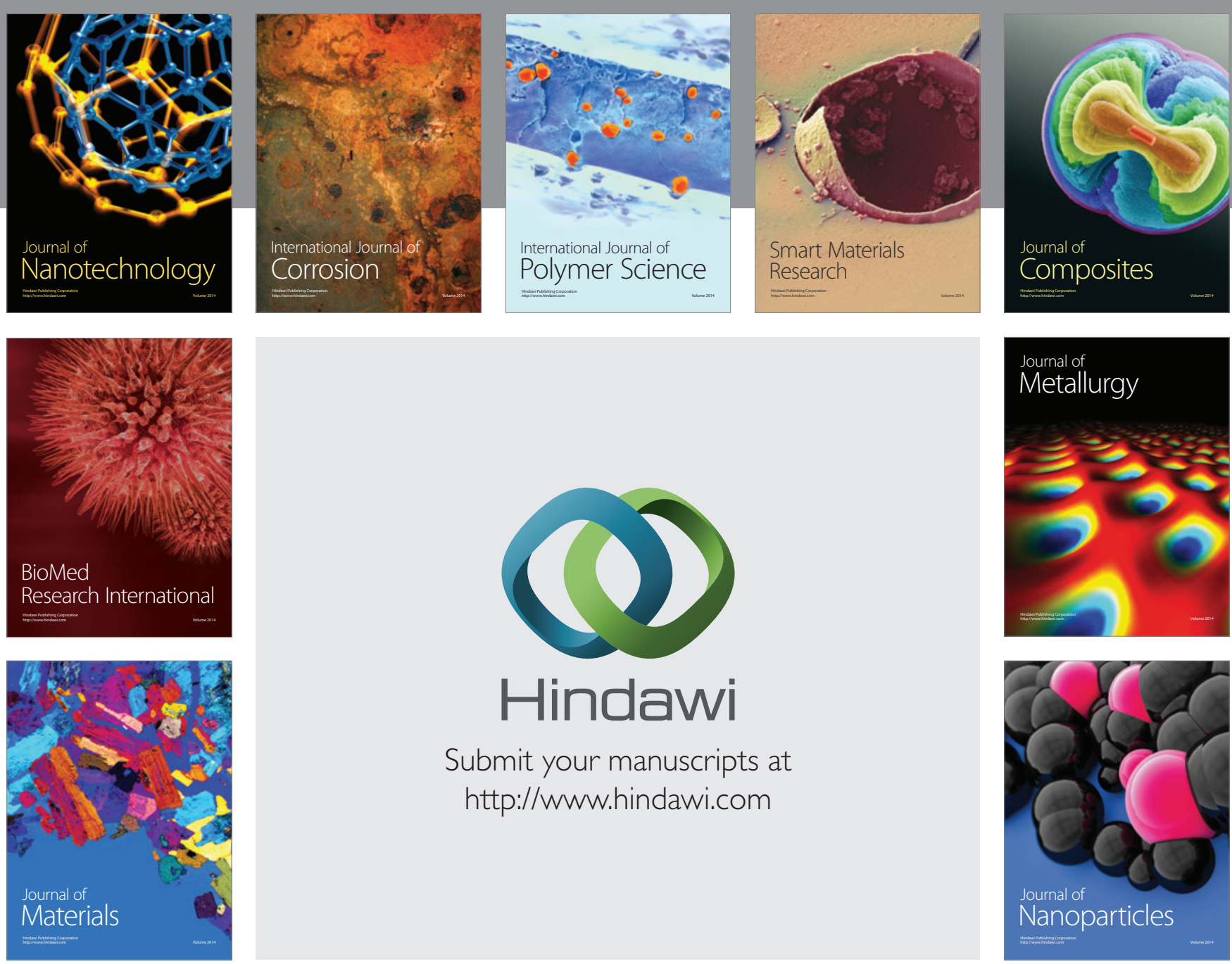

Submit your manuscripts at http://www.hindawi.com
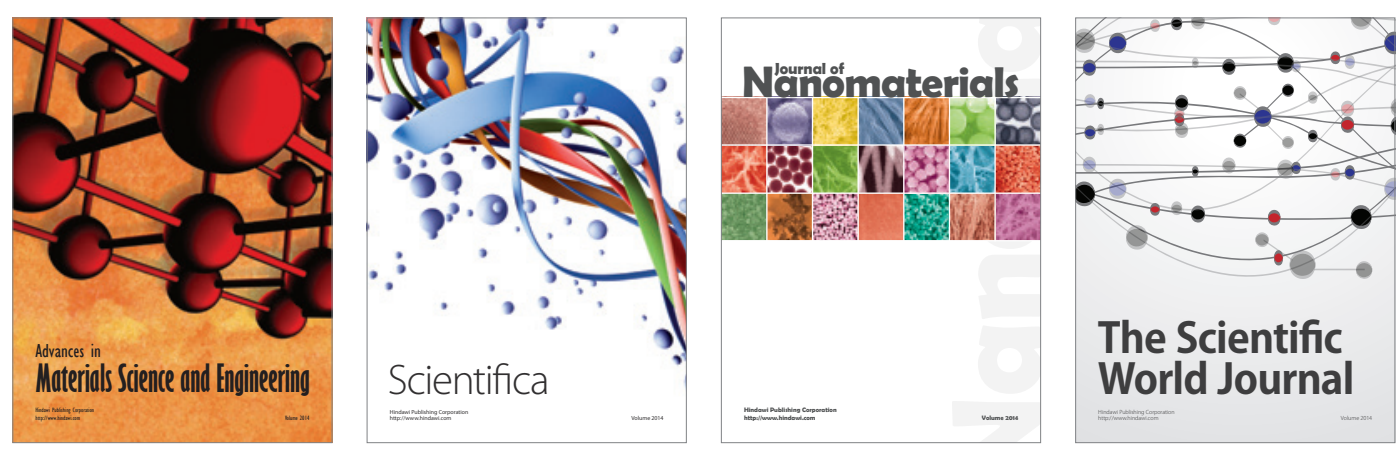

\section{The Scientific World Journal}
